\title{
In Memory of Anri Abramovich Bronshtein (October 2, 1935-July 20, 2010)
}

DOI: $10.1134 / \mathrm{S} 0018151 \mathrm{X} 11010032$

On July 20, 2010, Anri Abramovich Bronshteinone of the oldest employees of the Joint Institute for High Temperatures and translator of the journal Teplofizika vysokikh temperatur into its English version High Temperature - passed away suddenly at the age of 75 .

Since 1982, that is, from the first days that the English version began to be prepared directly in Russia (up until that time the journal had been translated in the United States), Bronshtein was an irreplaceable translator of this publication. He was well versed in the subject matter of the journal and worked in close contact with authors, ensuring exact translations of papers and maintaining scientific value of information. His conscientiousness, sense of obligation, and very high professionalism distinguished him in his work.

Bronshtein was born on October 2, 1935. In 1959 he graduated from Moscow's Herzen Pedagogical Institute, and in 1969 he went to work at the Institute of High Temperatures, USSR Academy of Sciences, where he was employed right up to the last days of his life. A leading specialist of the institute's department of international relations, he was a devoted participant of nearly all international functions and made an inestimable contribution to the development of SovietAmerican cooperation in the field of MHD energy transformation. Bronshtein translated into English many reports and monographs by colleagues of the Joint Institute for High Temperatures of the Russian Academy of Sciences.

A remarkable human being and a high-class specialist has departed from this world. His memory will live on in our hearts.

Editorial Board and Publisher, Teplofizika vysokikh temperatur 